\title{
Comparison of a commercial test for serotyping heat-stable antigens of Campylobacter jejuni with genotyping by pulsed-field gel electrophoresis
}

\author{
HILPI RAUTELIN and MARJA-LIISA HÄNNINEN* \\ Department of Bacteriology and Immunology, The Haartman Institute, University of Helsinki and Helsinki \\ University Central Hospital Diagnostics and *Department of Food and Environmental Hygiene, Faculty of \\ Veterinary Medicine, University of Helsinki, Finland
}

\begin{abstract}
A new commercial serotyping set based on heat-stable Penner's antigens was compared with pulsed-field gel electrophoresis (PFGE) with SmaI and Sac II restriction endonucleases. Among 50 isolates of Campylobacter jejuni from Finnish patients, which represented predominant PFGE patterns selected from isolates from sporadic cases and isolates associated with small outbreaks, 11 different serotypes were demonstrated from 43 typable isolates. Several PFGE patterns could be found within one serotype; on the other hand, several serotypes could be demonstrated within one PFGE type. Most isolates originated from sporadic cases; however, some isolates were epidemiologically associated and showed identical serotypes and PFGE patterns. Although the new serotyping set would have been useful in the few epidemic cases studied, several isolates (14\%) representing the major PFGE patterns remained untypable or gave weakly positive agglutination reactions only suggesting a plausible serotype $(18 \%)$. This might restrict the use of the novel serotyping set, at least in Finland.
\end{abstract}

\section{Introduction}

Campylobacter jejuni is the most common bacterial enteropathogen in developed countries [1-3]. In 1997 in Finland, 2397 bacteriologically verified cases were reported (National Infectious Disease Registry, National Public Health Institute, Helsinki, Finland). Most campylobacter cases are sporadic, but small outbreaks occur, mostly within families. Handling and eating poultry, and drinking contaminated water and unpasteurised milk have been shown to be risk factors and have been associated with epidemics [3].

As the sources and routes of transmission of this organism are not fully understood, a readily available discriminatory typing method would be helpful. So far, serotyping based on heat-stable [4] or heat-labile [5] antigens has been most widely used for typing of Campylobacter isolates. However, the lack of commercially available antisera has restricted the use of these methods in smaller laboratories without antisera collec-

Received 29 June 1998; revised version accepted 19 Oct. 1998.

Corresponding author: Dr H. Rautelin. tions of their own. Different DNA-based molecular methods have also been applied [6-9]. Pulsed-field gel electrophoresis (PFGE) has been shown to be a particularly discriminatory method if two restriction enzymes, SmaI and KpnI or Sac II, are used [6, 10-12].

PFGE has been used successfully to type $C$. jejuni isolates of human and chicken origin [12]. However, PFGE is limited to specialised laboratories and serotyping would be more practical in clinical laboratories. Therefore, 50 human isolates of $C$. jejuni that represented both predominant PFGE patterns and those associated with small outbreaks were selected and serotyped with a novel commercial serotyping set.

\section{Materials and methods}

\section{C. jejuni isolates}

Fifty human $C$. jejuni isolates of domestic origin were studied. The strains were isolated from 50 Finnish patients with enteritis who had acquired their infection from domestic sources in 1995-1996. All isolates were gram-negative and oxidase, catalase and hippurate positive, and they grew at $37^{\circ} \mathrm{C}$ and $43^{\circ} \mathrm{C}$ in an atmosphere of $\mathrm{O}_{2} 5 \%, \mathrm{CO}_{2} 10 \%, \mathrm{~N}_{2} 85 \%$. After the original isolation, the isolates were stored at $-70^{\circ} \mathrm{C}$. 
Forty-five isolates from sporadic campylobacter cases were selected from a total of 107 domestic isolates studied earlier and represented the most common PFGE genotypes found amongst them [12]. In addition, sets of three and two isolates from patients with possible epidemiological associations (based on a questionnaire) were included. Some details of the patients from whom the strains studied were isolated are given in Table 1.

\section{Serotyping}

A new commercially available serotyping set (Campylobacter Antisera 'Seiken' Set, Denka Seiken, Japan) based on Penner's heat-stable serogroups was used. The test was a passive haemagglutination assay in which campylobacter antigens were extracted by nitrite and absorbed on to chicken red blood cells. The sensitised chicken erythrocytes were then agglutinated with antisera. According to the manufacturer's instructions, bacteria were harvested from agar plates, suspended in saline and extraction reagents 1 and 2 were added. After incubation for $10 \mathrm{~min}$ at room temperature, extraction reagent 3 was added and, after centrifugation, the supernate was used to sensitise aldehyde-fixed chicken red blood cells for $30 \mathrm{~min}$ at $37^{\circ} \mathrm{C}$. After centrifugation, the supernate was discarded and the pellet was resuspended in buffer. One drop of each antiserum was placed individually into microtitration wells and sensitised chicken red blood cell suspensions were added. Microtitration plates were mixed and placed in a moist box and incubated for $30 \mathrm{~min}$. To control for spontaneous agglutination, control serum was used instead of antiserum. The heat-stable serotypes against which antisera were included in the panel are shown in Table 2.

\section{Genotyping}

For PFGE analysis, the isolates were grown on Brucella blood agar for 2 days at $37^{\circ} \mathrm{C}$ in a micro-aerobic atmosphere. The bacterial cells were harvested and treated with formaldehyde to inactivate endogeneous nucleases [13]. Otherwise, DNA was prepared as described earlier [14]; 2-mm slices of the agar plugs were digested with $S m a$ I or SacII (New England Biolabs, Hertfordshire) as described by the manufacturer. The DNA fragments were separated with Gene Navigator (Pharmacia LKB Biotechnology AB, Uppsala, Sweden) in agarose $1 \%$ gel in $0.5 \times \mathrm{TBE}(45 \mathrm{mM}$ Tris, $45 \mathrm{mM}$ boric acid, $1 \mathrm{mM}$ EDTA) at $200 \mathrm{~V}$. Sma I fragments were separated with ramped pulse from 0.5 to $25 \mathrm{~s}$ for $20 \mathrm{~h}$ and $S a c$ II fragments were separated with ramped pulse from 0.3 to $18 \mathrm{~s}$ for $20 \mathrm{~h}$. The guidelines of Tenover et al. were used for the interpretation of PFGE results [15]. SmaI patterns were designated by roman numerals and, if isolates with a certain pattern could be further subdivided by Sac II, the additional patterns were designated by capital letters (e.g., I/B).

\section{Results}

The haemagglutination patterns were recorded as negative $(-)$, weakly positive $(1+)$, moderately positive $(2+)$ and strongly positive $(3+)$. The interpretation of the serotyping results was as follows. Strongly (24 isolates) or moderately (four isolates) positive reactions with a single antiserum only were regarded as significant. Isolates with such reactions with several antisera were considered to be complex serotypes (six isolates). Weakly positive reactions in addition to moderately or strongly positive reactions (nine isolates) were not considered significant. However, in cases with weakly positive reactions with a single antiserum only (nine isolates), the serotype was regarded as plausible. On the basis of this interpretation, seven isolates (14\%) remained untypable because they failed to agglutinate with any of the antisera available. Eleven different serotypes were found among the isolates tested (Table 1) and Pen 27 was the commonest. One serotype (the Pen 4, 13, 16, 43, 50 combination) was found only in complex types, i.e., in addition to another serotype antigen. In the case of serotype Pen 12, most (six of seven) of the reactions were weak, suggesting only a plausible serotype.

Several PFGE patterns were found within one serotype (Table 2). On the other hand, several serotypes were found within one PFGE pattern. For instance, SmaI/Sac II pattern I/B, which was the most prevalent type and was found in 18 isolates, was found among 4 different serotypes, and 12 of 13 isolates of serotype Pen 27 belonged to this PFGE pattern. Most isolates studied originated from sporadic cases of enteritis. However, data available from a questionnaire revealed that three patients had been on the same cruise ship, and the strains isolated from these patients showed both identical serotype (Pen 21), and SmaI (XI) and SacII patterns (R). Furthermore, two other patients were known to have had the same source (pheasants) of infection, and their isolates showed identical serotypes (Pen 1, 44) and SmaI types (IV). Examples of PFGE profiles are given in Fig. 1.

\section{Discussion}

Discriminatory typing methods are needed in the investigation of campylobacter outbreaks and for tracing the possible routes of transmission in sporadic campylobacter infections. However, even to prevent sporadic cases of campylobacter infection, a better understanding of sources of infection and routes of transmission is needed. A serotyping scheme based on heat-stable antigens has been applied in the investigation of sporadic campylobacter infections and outbreaks. The heat-stable antigens involved were originally assumed to be lipopolysaccharide [4], but a recent report suggested that the important antigens 
Table 1. Characteristics of $50 \mathrm{C}$. jejuni positive patients with domestically acquired isolates

\begin{tabular}{|c|c|c|c|c|c|c|}
\hline $\begin{array}{l}\text { Patient } \\
\text { no. }\end{array}$ & Sex & $\begin{array}{c}\text { Age } \\
\text { (years) }\end{array}$ & $\begin{array}{l}\text { Duration } \\
\text { of illness } \\
\text { (days) }\end{array}$ & $\begin{array}{l}\text { Fever } \\
\geqslant 38^{\circ} \mathrm{C}\end{array}$ & $\begin{array}{l}\text { Hospitalised } \\
\text { because of } \\
\text { diarrhoea }\end{array}$ & $\begin{array}{l}\text { Suspected } \\
\text { source of } \\
\text { infection* }\end{array}$ \\
\hline 1. & M & 8 & 6 & Yes & No & $?$ \\
\hline 2. & $F$ & 66 & 7 & Yes & Yes & $?$ \\
\hline 3. & M & 1 & 5 & Yes & Yes & $?$ \\
\hline 4. & $F$ & 41 & 2 & Yes & Yes & $?$ \\
\hline 5. & M & 67 & 5 & No & No & Chicken \\
\hline 6. & $F$ & 37 & 7 & Yes & Yes & Water \\
\hline 7. & $F$ & $<1$ & NK & NK & NK & NK \\
\hline 8. & $\mathrm{~F}$ & 63 & 6 & No & Yes & $?$ \\
\hline 9. & M & 32 & NK & NK & NK & NK \\
\hline 10. & $\mathrm{~F}$ & 70 & 4 & Yes & No & Soup \\
\hline 11. & M & 76 & 5 & Yes & Yes & $?$ \\
\hline 12. & $\mathrm{~F}$ & 83 & NK & NK & NK & NK \\
\hline 13. & $\mathrm{~F}$ & 40 & 10 & No & No & $?$ \\
\hline 14. & M & 22 & NK & NK & NK & NK \\
\hline 15. & M & 20 & NK & $\mathrm{NK}$ & NK & NK \\
\hline 16. & M & 71 & 7 & Yes & Yes & Water \\
\hline 17. & $F$ & 43 & 5 & No & No & Water \\
\hline 18. & $\mathrm{M}$ & 2 & 17 & No & Yes & Water \\
\hline 19. & M & 31 & NK & NK & NK & NK \\
\hline 20. & $\mathrm{~F}$ & 38 & 5 & Yes & No & Chicken \\
\hline 21. & $\mathrm{~F}$ & 54 & 7 & No & No & Chicken \\
\hline 22. & $\mathrm{~F}$ & 29 & 7 & Yes & No & $?$ \\
\hline 23. & $\mathrm{~F}$ & 51 & NK & NK & NK & NK \\
\hline 24. & M & 59 & 16 & No & Yes & $?$ \\
\hline 25. & M & 74 & 7 & Yes & Yes & $?$ \\
\hline 26. & $\mathrm{~F}$ & 20 & 6 & Yes & Yes & Chicken \\
\hline 27. & F & 21 & NK & NK & NK & NK \\
\hline 28. & M & 22 & 6 & Yes & Yes & Restaurant \\
\hline 29. & $\mathrm{~F}$ & 71 & 4 & Yes & No & Cruise \\
\hline 30. & M & 79 & 6 & Yes & Yes & Cruise \\
\hline 31. & $\mathrm{M}$ & 67 & 7 & No & No & Cruise \\
\hline 32. & M & 69 & 5 & No & No & $?$ \\
\hline 33. & M & 63 & 9 & Yes & Yes & Pheasants \\
\hline 34. & $\mathrm{M}$ & 59 & 4 & Yes & Yes & Pheasants \\
\hline 35. & $\mathrm{~F}$ & 52 & 4 & Yes & Yes & Fish \\
\hline 36. & $F$ & 54 & 7 & Yes & No & Chicken \\
\hline 37. & $F$ & 77 & 10 & Yes & Yes & Water \\
\hline 38. & $\mathrm{~F}$ & 47 & 8 & Yes & Yes & $?$ \\
\hline 39. & $\mathrm{~F}$ & 20 & 5 & Yes & Yes & $?$ \\
\hline 40. & M & 31 & 2 & Yes & Yes & $?$ \\
\hline 41. & $\mathrm{M}$ & 26 & 7 & Yes & No & $?$ \\
\hline 42. & M & 47 & 3 & Yes & No & Water \\
\hline 43. & $\mathrm{~F}$ & 62 & 4 & Yes & Yes & Chicken \\
\hline 44. & M & 17 & NK & NK & NK & NK \\
\hline 45. & M & 25 & 12 & Yes & No & $?$ \\
\hline 46. & M & 54 & NK & NK & NK & NK \\
\hline 47. & $\mathrm{~F}$ & 88 & NK & NK & NK & NK \\
\hline 48. & $\mathbf{M}$ & 68 & 7 & Yes & Yes & $?$ \\
\hline 49. & M & 26 & NK & NK & NK & NK \\
\hline 50. & $\mathrm{~F}$ & $<1$ & NK & NK & NK & NK \\
\hline
\end{tabular}

?, Patient could not identify the source; NK, not known, questionnaire not available. * Based on a questionnaire sent to the patient.

were more likely to be capsular carbohydrates [16]. However, the routine use of this serotyping system has been restricted in smaller laboratories without serum collections of their own, as many antisera are needed. Therefore, a simple commercially available typing set would be useful.

The serotyping system evaluated in the present study was easy to perform. However, 18 isolates tested gave weakly positive haemagglutination reactions. In nine cases, these were not considered significant as they were demonstrated in addition to clearly positive ( $2+$ or $3+$ ) reactions. According to the manufacturer, the weakly positive reactions should have been regarded as positive; however, in that case $14(28 \%)$ of the isolates studied would have been of complex type, presenting several heat-stable antigens. In nine cases with weak reactions with a single antiserum, serotypes (in six cases, serotype 12) were considered plausible, as otherwise the number of untypable isolates would have been unsatisfactorily high $(32 \%)$.

The serotyping panel for $C$. jejuni studied here included a set of antisera against 25 serotypes, and the Finnish domestic isolates reacted with only 11 of them. Furthermore, $14 \%$ of the isolates remained untypable even if weakly positive reactions were considered plausible. High figures of non-reactivity 
Table 2. Heat-stable serotypes and PFGE patterns with two restriction endonucleases ( $\mathrm{Sma}$ I/Sac II) of 50 Finnish $C$. jejuni isolates

\begin{tabular}{|c|c|c|c|c|c|c|c|c|c|c|c|c|c|c|c|}
\hline \multirow[b]{2}{*}{ Serotype } & \multicolumn{15}{|c|}{ Number of isolates with PFGE pattern $(\mathrm{SmaI} / \mathrm{Sac} \mathrm{II})$} \\
\hline & $\mathrm{I} / \mathrm{B}$ & $\mathrm{I} / \mathrm{C}$ & $\mathrm{I} / \mathrm{E}$ & $\mathrm{I} / \mathrm{J}$ & $\mathrm{I} / \mathrm{K}$ & $\mathrm{I} / \mathrm{L}$ & $\mathrm{I} / \mathrm{M}$ & $\mathrm{I} / \mathrm{N}$ & $\mathrm{I} / \mathrm{ND}$ & IV/IV & $\mathrm{V} / \mathrm{V}$ & $\mathrm{VI} / \mathrm{VI}$ & $\mathrm{VII} / \mathrm{VII}$ & $\mathrm{XI} / \mathrm{R}$ & $\mathrm{XI} / \mathrm{S}$ \\
\hline $1 / 44$ & $2^{\mathrm{W}}$ & & & & & & & & & $4^{*}$ & & & & & \\
\hline 2 & & & & & & & & & & & & & & & \\
\hline 3 & & & 1 & & & & & & & & & & $3^{\dagger w}$ & & \\
\hline $\begin{array}{l}4 / 13 / 16 / 43 / 50 \\
5\end{array}$ & $3^{\ddagger}$ & & & & & & & & & & & & $1^{\dagger}$ & & \\
\hline $6 / 7$ & & & & 1 & & & & & & 1 & & & & & \\
\hline 8 & & & & & & & & & & $2^{*}$ & & & & & \\
\hline 10 & & & & & & & & & & & & & & & \\
\hline 11 & & & & & & & & & & & & & & & \\
\hline 12 & $1^{\mathrm{W}}$ & $1^{\mathrm{W}}$ & & & $2^{\mathrm{W}}$ & & 1 & & $1^{\mathrm{W}}$ & & & $1^{\mathrm{w}}$ & & & \\
\hline $\begin{array}{l}15 \\
18\end{array}$ & & & & & & & & & & & & & & & \\
\hline 18 & & & & & & & & & & & & & & & \\
\hline 19 & & & & & & & & & & & 3 & & & & \\
\hline 21 & & & & & & & & & & & & & & 3 & 3 \\
\hline $23 / 36 / 53$ & & & & & & & & & & & 1 & & & & \\
\hline $27^{\prime}$ & $12^{\ddagger}$ & & & & & & & & & & & 1 & & & \\
\hline 31 & & & & & & & & & & & & & & & \\
\hline 32 & & & & & & & & & & & & & & & \\
\hline 37 & & & & & & & & & & & & & & & \\
\hline 38 & & & & & & & & & & & & & & & \\
\hline 41 & & & & & & 1 & & & & & & & & & \\
\hline 45 & & & & & & & & & & & & & & & \\
\hline 52 & & & & & & & & & & & & & & & \\
\hline 55 & & & & & & & & & & & & & & & \\
\hline 57 & & & & & & & & & & & & & & & \\
\hline NT & & & & & & & & 1 & 1 & & & 2 & 3 & & \\
\hline
\end{tabular}

ND, not done; NT, not typable

${ }^{*}$ Two strains with complex serotypes $8+1,44 ;{ }^{\dagger}$ one strain with a complex serotype $3+(4,13,16,43,50) ;{ }^{\ddagger}$ three strains with complex serotypes $27+(4,13,16,43,50)$; ${ }^{\mathrm{w}}$ weak reaction, plausible serotype.

kb $\quad$ mw 12334567 mw 89101112131415161718192021

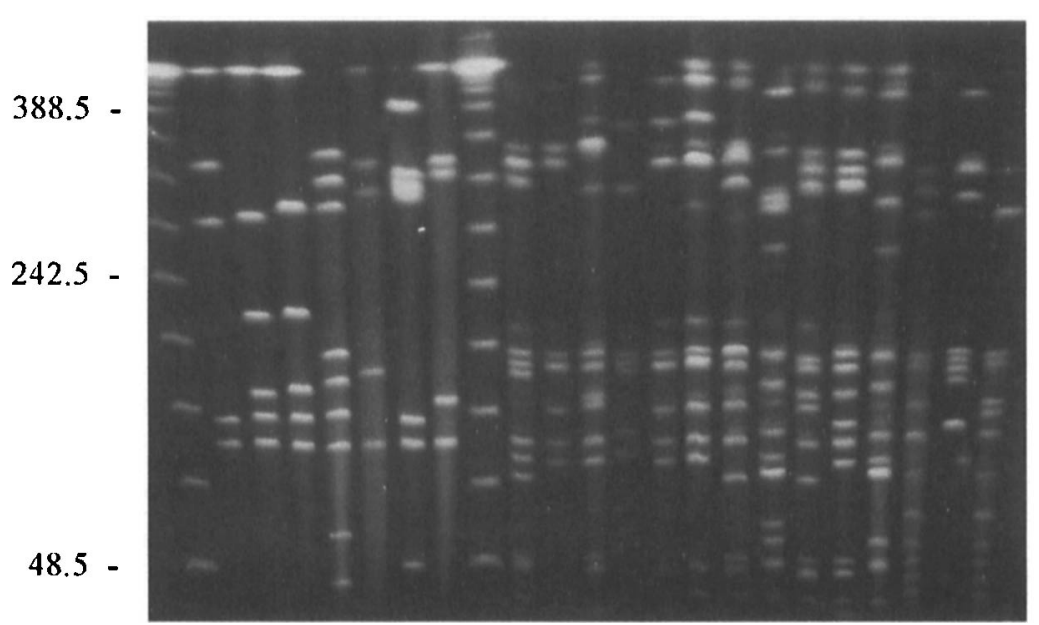

Fig. 1. Selected SmaI and SacII patterns of $C$. jejuni strains used for serotyping. Lanes 1-7 represent various $S m a \mathrm{I}$ pattern types, and lanes 8-21 various Sac II patterns, respectively. SmaI pattern types: lane 1, type I; 2, type XI; 3, type XI; 4, type IV 5, type VII; 6, type V; 7, type VI. SacII patterns: lane 8, type J; 9, type K; 10, type B; 11, type L; 12, type $M ; 13$, type $C ; 14$, type $N ; 15$, type $T ; 16$, type $S ; 17$, type R; 18, type IV; 19 , type VII; 20, type V; 21, type $\mathrm{VI}$; mw, molecular size marker $\lambda$ concatamer $(48.5 \mathrm{~kb})$; sizes are shown on the left.

with commercially available antisera have also been described previously for test kits based on heat-labile antigens $[17,18]$, whereas a considerably higher percentage of isolates has been typable with a larger set of antisera [11, 19]. In Sweden, among Campylobacter isolates from patients with domestically acquired infections, the heat-stable serotypes 2, 4, 6 and 8 covered more than half of all serotypes [20].
These specific serotypes were also among the 10 commonest ones identified in the USA [19]. In a previous study, PFGE types I, IV, V, VI and VII covered $42 \%$ of all domestic isolates detected at the Department of Bacteriology and Immunology, University of Helsinki [12]. However, in the present study, some isolates representing these prevalent PFGE types remained untypable in serotyping. 
PFGE analysis has been shown to be a highly discriminatory method in the identification of different C. jejuni isolates if a combination of two restriction endonucleases, SmaI and KpnI or SacII is used $[6,10-12]$. In the present study, some isolates with different PFGE patterns were found within a single heat-stable serotype. This has been reported previously [11] and is in accordance with the higher discriminatory power of DNA-based methods. However, from a reverse perspective, some strains with different serotypes produced identical PFGE patterns. A similar phenomenon was described [21] with the demonstration of different serotypes within a single PCR fingerprint among campylobacters isolated from animal sources [21]. Furthermore, one PFGE pattern or closely related patterns within several serotypes have been reported [11].

In this study, only five isolates were known to be epidemiologically associated with each other. In these particular cases, both serotyping and PFGE gave concordant results. However, further studies are needed to show the value of this serotyping set in the investigation of larger campylobacter epidemics.

In conclusion, a new commercially available serotyping set based on heat-stable serotypes was compared with PFGE profiling. Different PFGE patterns were found within a single serotype and vice versa, and a considerable number of isolates remained untypable or gave weakly positive reactions only in serotyping. The new serotyping method was rapid and easy to perform, but if the set had included more antisera the number of untypable strains may have been lower.

The technical assistance of Ms Urzula Hirvi and Ms Eila Kelo is gratefully acknowledged. This study was supported by the Yrjö Jahnsson Foundation, Helsinki, and Finnish Veterinary Medical Association, Helsinki, Finland.

\section{References}

1. Rautelin HI, Renkonen $\mathrm{O}-\mathrm{V}$, von Bonsdorff $\mathrm{C}-\mathrm{H}$ et al. Prospective study of the etiology of diarrhea in adult outpatients and inpatients. Scand J Gastroenterol 1989; 24: $329-333$.

2. Skirrow MB. A demographic survey of campylobacter, salmonella and shigella infections in England. A Public Health Laboratory Service Survey. Epidemiol Infect 1987; 99: 647-657.

3. Tauxe RV. Epidemiology of Campylobacter jejuni infections in the United States and other industrialized nations. In: Nachamkin I, Blaser MJ, Tomkins LS (eds) Campylobacter jejuni: current status and future trends. Washington, DC, American Society for Microbiology. 1992: 9-19.

4. Penner JL, Hennessy JN, Congi RV. Serotyping of Campylo- bacter jejuni and Campylobacter coli on the basis of thermostable antigens. Eur J Clin Microbiol 1983; 2: 378-383.

5. Lior $\mathrm{H}$, Woodward DL, Edgar JA, Laroche LJ, Gill P. Serotyping of Campylobacter jejuni by slide agglutination based on heat-labile antigenic factors. J Clin Microbiol 1982; 15: $761-768$.

6. Gibson JR, Fitzgerald C, Owen RJ. Comparison of PFGE, ribotyping and phage-typing in the epidemiological analysis of Campylobacter jejuni serotype HS2 infections. Epidemiol Infect 1995; 115: 215-225.

7. Hernandez J, Fayos A, Ferrus MA, Owen RJ. Random amplified polymorphic DNA fingerprinting of Campylobacter jejuni and $C$. coli isolated from human faeces, seawater and poultry products. Res Microbiol 1995; 146: 685-696.

8. Hernandez J, Fayos A, Alonso J-L, Owen RJ. Ribotypes and AP-PCR fingerprints of thermophilic campylobacters from marine recreational water. $J$ Appl Bacteriol 1996; 80: 157-164.

9. Ayling GK, Woodward MJ, Evans S, Newell DG. Restriction fragment length polymorphism of polymerase chain reaction products applied to the differentiation of poultry campylobacters for epidemiological investigations. Res Vet Sci 1996; 60: $168-172$.

10. Suzuki Y, Ishihara $M$, Saito $M$, Ishikawa $N$, Yokochi $T$. Discrimination by means of pulsed-field gel electrophoresis between strains of Campylobacter jejuni Lior type 4 derived from sporadic cases and outbreaks of infection. J Infect 1994; 29: $183-187$.

11. Gibson J, Lorenz E, Owen RJ. Lineages within Campylobacter jejuni defined by numerical analysis of pulsed-field gel electrophoretic DNA profiles. $J$ Med Microbiol 1997; 46: $157-163$.

12. Hänninen M-L, Pajarre S, Klossner M-L, Rautelin H. Typing of human Campylobacter jejuni isolates in Finland by pulsedfield gel electrophoresis. J Clin Microbiol 1998; 36: 1787-1789.

13. Gibson JR, Sutherland K, Owen RJ. Inhibition of DNAse activity in PFGE analysis of DNA from Campylobacter jejuni. Lett Appl Microbiol 1994; 19: 357-358.

14. Maslow JN, Slutsky AM, Arbeit RD. Application of pulsedfield gel electrophoresis to molecular epidemiology. In: Pershing DH, Smith TF, White TJ (eds) Diagnostic molecular medicine. Principles and applications. Washington, DC, American Society for Microbiology. 1993: 563-572.

15. Tenover FC, Arbeit RD, Goering $\mathrm{RV}$ et al. Interpreting chromosomal DNA restriction patterns produced by pulsedfield gel electrophoresis: criteria for bacterial strain typing. $J$ Clin Microbiol 1995; 33: 2233-2239.

16. Chart H, Frost JA, Oza A, Thwaites R, Gillanders S, Rowe B. Heat-stable serotyping antigens expressed by strains of Campylobacter jejuni are probably capsular and not long-chain lipopolysaccharide. J Appl Bacteriol 1996; 81: 635-640.

17. Nicholson MA, Patton CM. Evaluation of commercial antisera for serotyping heat-labile antigens of Campylobacter jejuni and Campylobacter coli. J Clin Microbiol 1993; 31: 900-903.

18. Bär W, Fricke G, Goossens H. Distribution of serotypes and biotypes of thermophilic campylobacters in the Federal Republic of Germany: a comparison with other countries. Zentralbl Bakteriol 1989; 271: 127-134.

19. Patton CM, Nicholson MA, Ostroff SM, Ries AA, Wachsmuth IK, Tauxe RV. Common somatic $\mathrm{O}$ and heat-labile serotypes among Campylobacter strains from sporadic infections in the United States. J Clin Microbiol 1993; 31: 1525-1530.

20. Sjögren E, Alestig K, Kaijser B. Campylobacter strains from Swedish patients with diarrhoea. Distribution of serotypes over a five year period. APMIS 1989; 97: 221-226.

21. Aarts HJM, van Lith LAJT, Jacobs-Reitsma WF. Discrepancy between Penner serotyping and polymerase chain reaction fingerprinting of Campylobacter isolated from poultry and other animal sources. Lett Appl Microbiol 1995; 20: 371-374. 